\title{
Antiproliferative and apoptotic effect of epigallocatechin- 3-gallate on Ishikawa cells is accompanied by sex steroid receptor downregulation
}

\author{
SEUNG BIN PARK ${ }^{1}$, JONG WOON BAE ${ }^{1}$, JONG MIN KIM ${ }^{2}$, SEUNG GEE LEE ${ }^{2}$ and MYOUNGSEOK HAN ${ }^{1}$ \\ Departments of ${ }^{1}$ Obstetrics and Gynecology and ${ }^{2}$ Anatomy and Cell Biology, \\ Dong-A University, College of Medicine, Busan 602-715, Republic of Korea
}

Received May 17, 2012; Accepted July 9, 2012

DOI: $10.3892 /$ ijmm.2012.1104

\begin{abstract}
Endometrial cancer is a significant malignancy in developed countries. Unopposed estrogen stimulation is considered as an important risk factor for endometrial cancer. Epigallocathechin-3-gallate (EGCG), biological active component of green tea, inhibits cancer cell proliferation. However, it is unknown whether EGCG has anticancer effects on endometrial cancer and what the molecular mechanism(s) are. We investigated the anticancer effects of EGCG on a human endometrial adenocarcinoma cell line (Ishikawa cells) with or without $17 \beta$-estradiol $\left(E_{2}\right)$ treatment. Cell proliferation assay was performed using 3-(4,5-dimethylthiaxol-2-yi)-2,5-diphenyltetraxolium bromide (MTT). The cell cycle was determined by flow cytometry and real-time analysis of cyclin and cdk genes. The apoptosis was measured by Annexin V-PI staining and real-time analysis of bcl-2, Bax and caspase genes. The MAPK signal, Akt and caspase-3 were determined by immunoblotting. Decreased estrogen and progesterone receptor expression was observed in EGCG-treated Ishikawa cells, and decreased MAPK signals and phospho-Akt were observed as well. EGCG caused the arrest of cells in the G0/G1 phase of the cell cycle. This compound interfered with Akt activation and MAPK signals, and increased apoptosis signals leading to a controlled caspases, Bcl-2, Bax genes and protein expression. Taken together, EGCG inhibits cell proliferation and induces apoptosis through Akt and MAPK signals. These findings suggest that EGCG may exert growthinhibitory and apoptosis-inducing effects on endometrial cancer cells, accompanied by decreased estrogen and progesterone receptor. EGCG may have future clinical implications with respect to the development of novel approaches as an adjuvant therapy in endometrial cancer.
\end{abstract}

Correspondence to: Professor Myoungseok Han, Department of Obstetrics and Gynecology, Dong-A University School of Medicine, Dondaeshin-dong 3-ga, Seo-gu, Busan 602-715, Republic of Korea E-mail: hmsobgy@dau.ac.kr

Key words: epigallocatechin-3-gallate, endometrial carcinoma, estrogen receptor, progesterone receptor

\section{Introduction}

Endometrial cancer is the most common gynecological malignancy in western countries, and its incidence has recently increased (1). The risk factors of endometrial adenocarcinoma include nulliparity (2), late menopause onset (3) and use of estrogen-only hormone replacement therapy (HRT) (4). An exposure to high estrogen and low progesterone levels increases proliferation of endometrial cells, and therefore the risk of cancer development of endometrial adenocarcinoma (5).

Among various risk factors, estrogens are well recognized to play a significant role in endometrial cancer development and growth (6). Estradiol has been shown to exert its proliferative and anti-apoptotic effects through the Akt activation in human endometrial cells (7). Estrogen acts via the estrogen receptor, which hormone induce the estradiol activation of the estrogen signal members and their mutual communication (8).

Estrogen receptor and progesterone receptors belong to the steroid hormone nuclear receptor superfamily and their upregulation in Ishikawa cell is induced by estradiol treatment (9). They are ligand-activated transcription factors involved in hormone-mediated signaling, hormone-mediated gene expression, and cellular proliferation and differentiation.

MAPK pathway is involved in the control of many fundamental cellular functions that include cell proliferation, survival, differentiation, apoptosis and metabolism (10).

Green tea has been studied extensively for its health benefits, including anticancer and cancer chemopreventive properties (11). Green tea contains a variety of polyphenols known as catechins. (-)-epigallocathechin-3-gallate (EGCG) is a major component of polyphenols in green tea (12). EGCG interacts with various molecules such as proteins, transcription factors, and enzymes, which block multiple stages of carcinogenesis via the regulation of intracellular signaling transduction pathways. EGCG possesses pharmacological and physiological properties including induction of phase II enzymes, mediation of anti-inflammation response, regulation of cell proliferation and apoptosis effects and prevention of tumor angiogenesis, invasion and metastasis (13). However, the EGCG amounts used in previous studies seem too high to explain the anticancer effect associated with green tea, compared with the levels measured in human blood and serum after oral consumption (14). Several 
mechanisms of cancer inhibition by EGCG in vivo have been proposed. It is reported that EGCG inhibited angiogenesis and matrix metalloproteinase in vivo (15). It is also reported that EGCG prevented the carcinogenesis of cervical cancer, induced apoptosis and inhibited telomerase activity (16).

The present study was undertaken to evaluate antiproliferative effects on human endometrial adenocarcinoma cell line, Ishikawa cell under the influence of EGCG. The anti-proliferative mechanism of action of EGCG was determined by studying the ER-mediated signaling and modulation of downstream genes involved in cell proliferation and apoptosis. We report that EGCG inhibits proliferation via modulating ER-dependent signaling mechanisms, interfere with Akt activation and induce apoptosis via intrinsic and extrinsic pathway in human endometrial cancer cells.

\section{Materials and methods}

Reagents and cell culture. Antibodies for caspase-3,-9, Akt,ERK, P38 and each phospho-form were purchased from Cell Signaling Technology. Enhanced chemiluminescence (ECL) was obtained from ELPIs Biotechnology, and other reagents were purchased from Sigma Chemical Co. (St. Louis, MO, USA). SYBR green was purchased from Agilent Technologies, and Tri reagent was purchased from Invitrogen (Carlsbad, CA). Human endometrial adenocarcinoma (Ishikawa) cells, which were kindly gifted by Dr Y.H. Kim at Asan Medical Center, Seoul, Korea, were grown in DMEM-F12 (Gibco, Invitrogen) supplemented with 10\% FBS at $37^{\circ} \mathrm{C}$ in $5 \% \mathrm{CO}_{2}$. Passages $4-8$ of cultures were used in all experiments.

Cell proliferation assay. The effects of EGCG on Ishikawa cells were assessed by MTT assay. Ishikawa cells (1x10 4 cells/ $\mathrm{ml}$ ) were incubated in a 96-well. The cells were incubated with EGCG, and cultured at $37^{\circ} \mathrm{C}$ under humidified atmosphere with $5 \% \mathrm{CO}_{2}$ for $24 \mathrm{~h}$. Subsequently, $20 \mu \mathrm{l}$ MTT solution $(5 \mathrm{mg} / \mathrm{ml}$ in PBS) was added to each well and placed at room temperature for $4 \mathrm{~h}$. The absorbance was measured on an ELISA reader at a wavelength of $495 \mathrm{~nm}$.

Reverse transcription-polymerase chain reaction (RT-PCR). RT-PCR was used to analyze the expression of mRNA for cell cycle factors, apoptosis factors and $\beta$-actin (internal control) in estrogen-stimulated Ishikawa cells. The Ishikawa cells were treated with $100 \mu \mathrm{M}$ EGCG and $1 \mu \mathrm{M} \mathrm{E} \mathrm{E}_{2}$ for $24 \mathrm{~h}$, and total RNA was isolated using Tri-reagent. cDNA was generated from $0.2 \mu \mathrm{g}$ of total RNA using RevertAid First strand cDNA Synthesis kit (Fermentas, St. Leon-Rot, Germany). The primers used for amplification of each gene were as shown in Table I. Real-time PCR was performed on Applied Biosystems 7000 real-time PCR system (Life Technologies, Carlsbad, CA, USA) with SYBR green premix. The expression levels of genes were normalized to that of $\beta$-actin gene.

Western blot analyses. For immunodetection, cells were harvested and lysed in lysis buffer consisting of $20 \mathrm{mM}$ Tris, $137 \mathrm{mM} \mathrm{NaCl}, 2 \mathrm{mM}$ EDTA, 10\% glycerol, 1\% Triton X-100, Protease inhibitor (Sigma Chemical Co., MO, USA), and phosphatase inhibitor cocktail III (Calbiochem Co., USA). The cleared protein lysates were separated by $12 \%$ SDS-PAGE and transferred electrophoretically onto nitrocellulose membrane. Blots were blocked with 3\% non-fat dry milk in TBS, them incubated with primary antibody. The Akt, ERK, JNK, caspase-3 and-9 were assayed using anti Akt, ERK, JNK, caspase-3 and -9 antibody (Cell Signaling Technoligy, MA, USA). After washing, blots were incubated with anti-goat horseradish peroxidaseconjugated secondary antibodies for $1 \mathrm{~h}$. Immunodetection was carried out using an enhanced chemiluminescence peroxidase substrate solution (ELPIs Biotechnology, Taejeon, Korea). Each band was analyzed by densitometry for statistical comparisons.

Cell cycle analysis. Cells were seeded in 6-well plates and treated with EGCG and $\mathrm{E}_{2}$ for $24 \mathrm{~h}$. After treatment, cells were washed with PBS, fixed in $70 \%$ cold ethanol for $72 \mathrm{~h}$, and then stained with propidium iodide (PI) solution $(50 \mu \mathrm{g} / \mathrm{ml})$. Cell cycle distribution was analyzed with flow cytometry (Beckman Coulter Inc., Brea, CA, USA). The percentage of DNA content at different phases of the cell cycle was analyzed with Multicyclesoftware.

Annexin-V/propidium iodide labeling and flow cytometry assay. Annexin-V binding is indicative of early apoptosis (17). The cells were culture in 6-well plates and treated with EGCG for $24 \mathrm{~h}$. Adherent and non-adherent cells were probed with FITC-conjugated Annexin-V and PI (BD Bioscience, NJ, USA) for $15 \mathrm{~min}$. The staining profiles were determined with FACScan. Stained cells were observed by fluoromicroscopy (Zeiss, Oberkochen, Germany). The experiments were performed three times with three replicates in each.

Statistical analysis. The data are expressed as the mean \pm SD. The statistical significance of the difference in mean values was tested using one-way analysis of variance (ANOVA) and Student's t-test. Significance was defined as $\mathrm{P}<0.05$.

\section{Results}

EGCG inhibits Ishikawa cell proliferation. To investigate the effect of EGCG on Ishikawa cell stimulated with $\mathrm{E}_{2}$, we applied EGCG and $\mathrm{E}_{2}$ for 24, 48, and $72 \mathrm{~h}$. Inhibitory effects were not found at $24 \mathrm{~h}$, treated with 50 and $100 \mu \mathrm{M}$ of EGCG (data not shown). Comparable results were found for $\mathrm{E}_{2}$-stimulated cells which were significantly increased at 48 and $72 \mathrm{~h}$, this effect could be inhibited by treatment with EGCG, and high concentration of EGCG also inhibited cell proliferation without $\mathrm{E}_{2}$ treatment (Fig. 1). Therefore, $100 \mu \mathrm{M}$ EGCG treatment was selected for further experiments.

Effect of EGCG on the expression of estrogen and progesterone receptor. For the analysis of ER- $\alpha$ and PR expression differences, cells treated with EGCG were incubated with or without $1 \mu \mathrm{M} \mathrm{E}_{2}$ for $24 \mathrm{~h} . \mathrm{E}_{2}$ treatment induces association of estrogen receptor $\alpha$ (8). As shown on Fig. 2, $\mathrm{E}_{2}$ treated cells showed increased expressions of ER- $\alpha$ and PR. However, the increased expressions were strongly inhibited by EGCG with statistical significance.

EGCG induces cell cycle arrest in Iishikawa cells. To examine the mechanism responsible for EGCG mediated cell proliferation inhibition, cell cycle distribution was evaluated using flow 
Table I. Primers for gene expression.

\begin{tabular}{|c|c|c|}
\hline Gene & & Primers \\
\hline \multirow[t]{2}{*}{ Estrogen receptor } & S: & 5'-AAG AGC TGC CAG GCC TGC-3' \\
\hline & AS: & 5'-TTG GCA GCT CTC ATG TCT CC-3' \\
\hline \multirow[t]{2}{*}{ Progesterone receptor } & S: & 5'-AAC ACA AAA CCT GAC ACC TC-3' \\
\hline & AS: & 5'-CGT GTT TGT AGG ATC TCC AT-3' \\
\hline \multirow[t]{2}{*}{ Cyclin D1 } & S: & 5'-TCG CCA CCT GGA TGC TGG AG-3' \\
\hline & AS: & 5'-CAC CAG GAG CAG CTC CAT TTG-3' \\
\hline \multirow[t]{2}{*}{ Cyclin D3 } & S: & 5'-CTG CCT CCA GGA ACC ACA-3' \\
\hline & AS: & 5'-GCT TGA CTA GCC ACC GAA AT-3' \\
\hline \multirow[t]{2}{*}{ Cdk 2} & $\mathrm{~S}:$ & 5'-ATG GAG AAC TTC CAA AAG GTG-3' \\
\hline & AS: & 5'-CAG GCG GAT TTT CTT AAG CG-3' \\
\hline \multirow[t]{2}{*}{ Cdk4 } & $\mathrm{S}:$ & 5'-ACA AGT GGT GGA ACA GTC AAG-3' \\
\hline & AS: & 5'-GCA TAT GTG GAC TGC AGA AGA -3' \\
\hline \multirow[t]{2}{*}{ CCNA2 } & S: & 5'-TGG GCA CTG CTG CTA TGC T-3' \\
\hline & AS: & 5'-GCA ATA ACT GAT GGC AAA TAC TTG A-3' \\
\hline \multirow[t]{2}{*}{ CCNB2 } & $\mathrm{S}:$ & 5'-CCA CAC CTG AGG ATG TCT CCA T-3' \\
\hline & AS: & 5'-ATG CCA ACG CAC ATG TAC AGA-3' \\
\hline \multirow[t]{2}{*}{ CCNB1 } & S: & 5'-TTT CTG CTG GGT GTA GGT CCT T-3' \\
\hline & AS: & 5'-GCC ATG TTG ATC TTC GCC TTA-3' \\
\hline \multirow[t]{2}{*}{ Cdk 1} & S: & 5'-AAA ATT GGA GAA GGT ACC TAT-3' \\
\hline & AS: & 5'-CСС TTC СТC TTC ACT TTC TAG T-3' \\
\hline \multirow[t]{2}{*}{ Caspase-6 } & S: & 5'-ACT GGC TTG TTC AAA GG-3' \\
\hline & AS: & 5'-CAG CGT GTA AAC GGA G-3' \\
\hline \multirow[t]{2}{*}{ Caspase- 8} & $\mathrm{~S}:$ & 5'-ATG CAA ACT GGA TGA TGA CA-3' \\
\hline & AS: & 5'-GAT TAT CTT CAG CAG GCT CTT-3' \\
\hline \multirow[t]{2}{*}{ Caspase-10 } & S: & 5'-AAT CTG ACA TGC CTG GAG-3' \\
\hline & AS: & 5'-ACT CGG CTT CCT TGT CTA C-3' \\
\hline \multirow[t]{2}{*}{ Bcl-2 } & S: & 5'-GCT CTA AAA TCC ATC CAG-3' \\
\hline & AS: & 5'-ССТ СТC CAT CAT CAA СТT-3' \\
\hline \multirow[t]{2}{*}{ Bax } & S: & 5'-CCC GAG AGG TCT TTT TCC-3' \\
\hline & AS: & 5'-GCC TTG AGC ACC AGT TTG-3' \\
\hline \multirow[t]{2}{*}{ Bcl-XL } & $\mathrm{S}:$ & 5'-TTA CCT GAA TGA CCA CCT A-3' \\
\hline & AS: & 5'-ATT TCC GAC TGA AGA GTG A-3' \\
\hline \multirow[t]{2}{*}{ GAPDH } & S: & 5'-TGA ACG GGA AGC TCA CTG G-3' \\
\hline & AS: & 5'-TCC ACC ACC CTG TTGCTG TA-3' \\
\hline
\end{tabular}

cytometric analysis. The results showed that EGCG treated cells caused a significant inhibition of cell cycle progression in Ishikawa cells (Fig. 3). Cyclin D and Cdk 4 genes are responsible for the transition of cells from $\mathrm{G} 1$ phase. Cyclin A and Cdk 2 genes are from $\mathrm{S}$ phase, and cyclin B and Cdk 1 genes are from $\mathrm{M}$ phase. Real-time PCR analysis showed that mRNA expression level of G1-Cdk, M-Cdk, and S-Cdk genes were decreased after EGCG treatment (Table II). These results clearly showed that EGCG induced cell cycle arrest through the control of cyclin-Cdk complexes. 

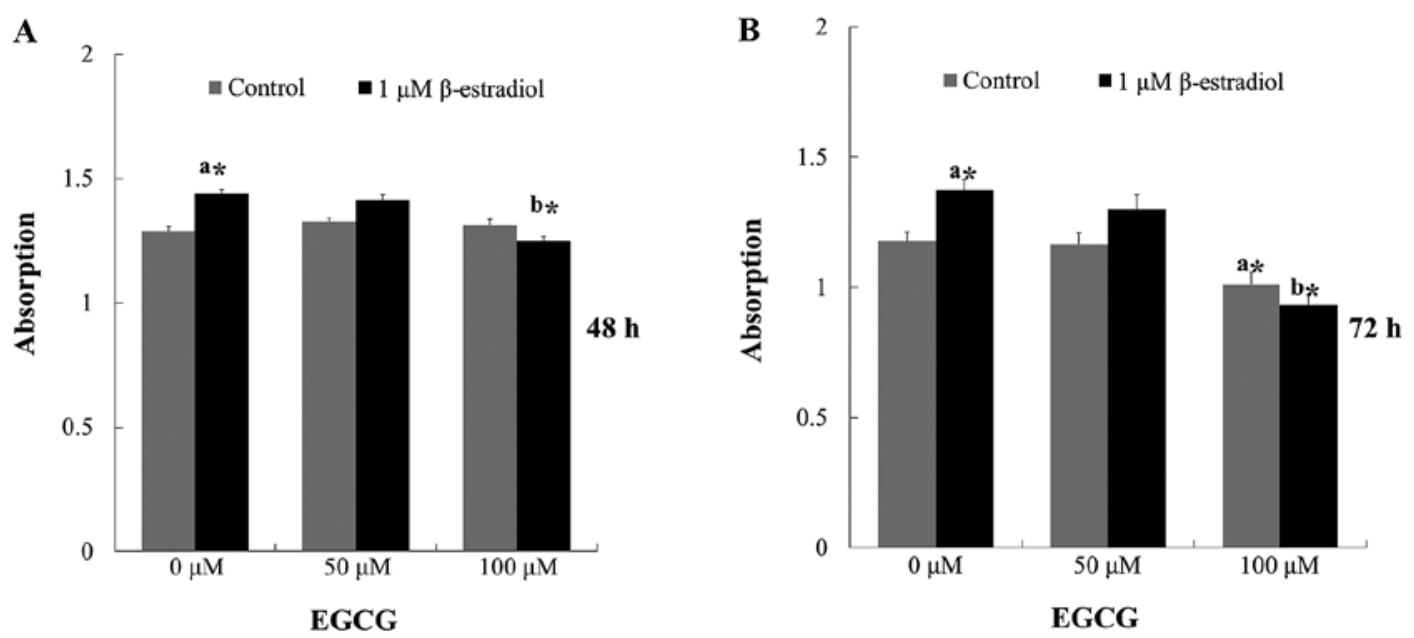

Figure 1. Effect of EGCG and $\beta$-estradiol on Ishikawa cell viability. (A) EGCG inhibited the growth of Ishikawa cells treated with $100 \mu \mathrm{M}$ EGCG for $48 \mathrm{~h}$ in the presence of $1 \mu \mathrm{M} \mathrm{E}_{2}$. (B) EGCG showed prominent antiproliferative effect on Ishikawa cells treated with $100 \mu \mathrm{M}$ EGCG for $72 \mathrm{~h}$ under the presence or absence of $1 \mu \mathrm{M} \mathrm{E}_{2}$. The level of cell proliferation was measured using MTT assay. The absorbance of viable cells was calculated. Each bar represents the mean \pm SEM of three independent experiments. ${ }^{\mathrm{a}}$ versus control; ${ }^{\mathrm{b}}$ versus 0 or $50 \mu \mathrm{M}$ of EGCG and $1 \mu \mathrm{M} \mathrm{E}_{2}$ treated. ${ }^{*} \mathrm{p}<0.05$.

A

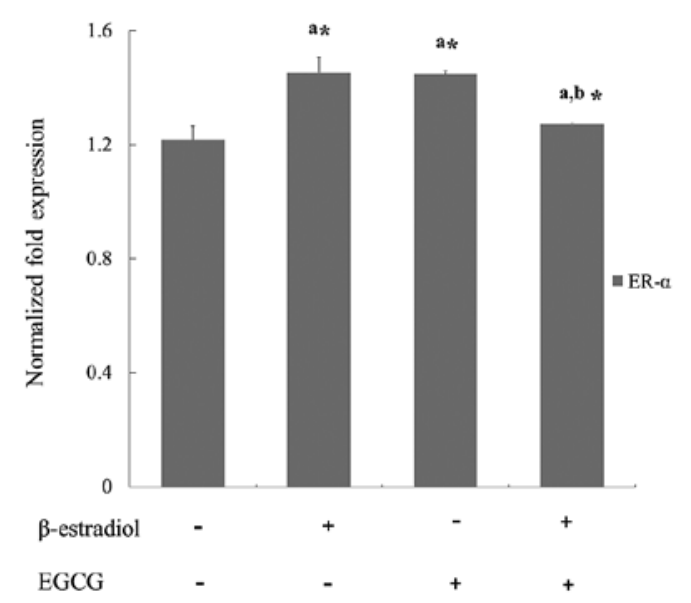

B

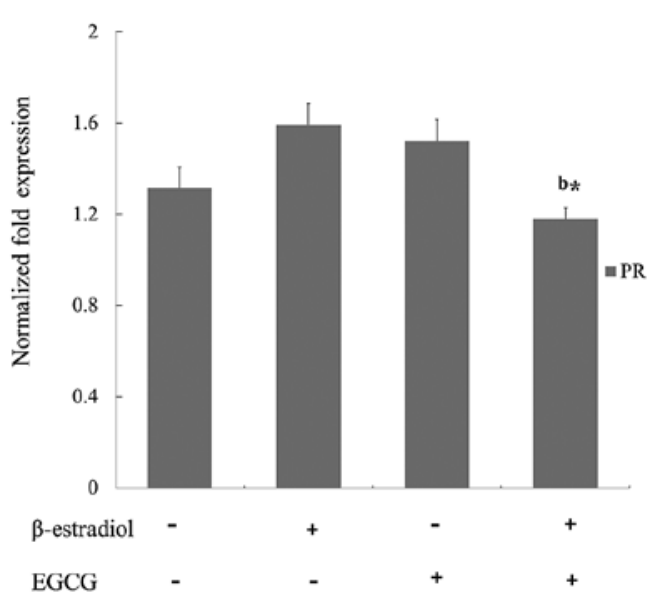

Figure 2. Effect of EGCG on expressions of ER- $\alpha$ and PR. Ishikawa cells incubated with $100 \mu \mathrm{M}$ EGCG and $1 \mu \mathrm{M} \mathrm{E} \mathrm{E}_{2}$ for $24 \mathrm{~h}$. Samples were subjected to real-time PCR with ER- $\alpha$ and PR primers. Equal amounts of RNA were performed in reverse transcription and of cDNA in real-time PCR. GAPDH was used as a control. Results are expressed as mean \pm SEM of three independent experiments. ${ }^{a} v s$ control; ${ }^{b} v s \mathrm{E}_{2}$ only treated. ${ }^{*} \mathrm{p}<0.05$.
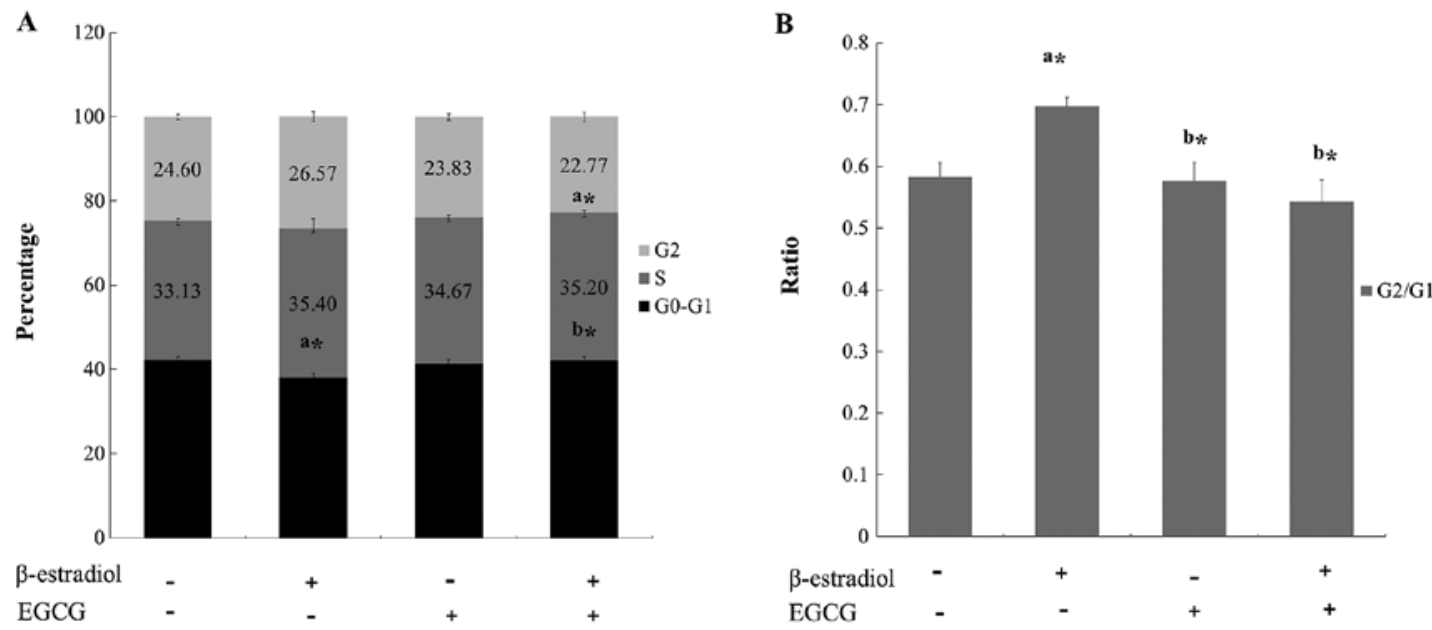

Figure 3. Effect of EGCG on the cell cycle by FACS. Ishikawa cells $\left(1 \times 10^{6} \mathrm{cells} / \mathrm{ml}\right)$ were preincubated with EGCG at $37^{\circ} \mathrm{C}$ for $24 \mathrm{~h}$ prior to incubation with $1 \mu \mathrm{ME}_{2}$. The cells stained with propidium iodide (PI) were subjected to flow cytometric analysis to determine the cell distributions at each phase of the cell cycle. Each value represents the mean \pm SEM of three independent experiments. ${ }^{a}$ versus control; ${ }^{b}$ versus $E_{2}$ only treated. ${ }^{*} p<0.05$. 
Table II. Effect of EGCG on $\mathrm{E}_{2}$ stimulated gene expression of the cell cycle from Ishikawa cells.

\begin{tabular}{lcccc}
\hline & \multicolumn{3}{c}{ Treatment } \\
\cline { 2 - 5 } Gene & None & $\beta$-estradiol & \multirow{2}{*}{ EGCG } & $\beta$-estradiol+EGCG \\
\hline Cdk 1 & $1.061 \pm 0.242$ & $3.502 \pm 0.871$ & $1.028 \pm 0.134$ & $1.157 \pm 0.200^{\mathrm{b}, \mathrm{c}}$ \\
Cyclin B1 & $3.126 \pm 0.686$ & $3.055 \pm 0.564$ & $1.694 \pm 0.046^{\mathrm{a}, \mathrm{c}}$ & $1.946 \pm 0.417$ \\
Cdk 2 & $1.460 \pm 0.244$ & $3.752 \pm 0.712$ & $2.264 \pm 0.512$ & $0.933 \pm 0.063^{\mathrm{b}, \mathrm{c}}$ \\
Cyclin A2 & $1.692 \pm 0.505$ & $2.196 \pm 0.446$ & $1.252 \pm 0.072^{\mathrm{a}, \mathrm{c}}$ & $1.177 \pm 0.291$ \\
Cyclin D1 & $1.035 \pm 0.112$ & $0.741 \pm 0.267$ & $1.472 \pm 0.620$ & $1.595 \pm 0.193$ \\
Cyclin D3 & $1.149 \pm 0.047$ & $2.515 \pm 0.924$ & $1.200 \pm 0.284$ & $1.414 \pm 0.094^{\mathrm{b}, \mathrm{c}}$ \\
Cdk 4 & $1.922 \pm 0.569$ & $2.319 \pm 0.418$ & $1.327 \pm 0.140$ & $1.131 \pm 0.246$ \\
\hline
\end{tabular}

Real-time PCR was used to compare the change in the cyclin and cdc gene mRNA expression in the EGCG treated Ishikawa cells. Results are expressed as mean $\pm \mathrm{SE}, \mathrm{n}=3$. ${ }^{\mathrm{a}} \mathrm{vs}$ control; ${ }^{\mathrm{b}} \mathrm{vs} \mathrm{E} 2$ only treated. ${ }^{\mathrm{c}} \mathrm{p}<0.05$.

$\mathbf{A}$

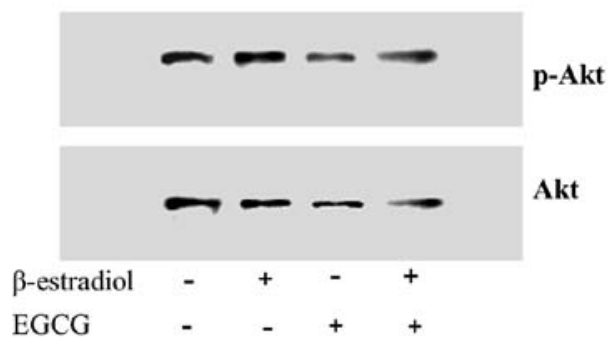

B

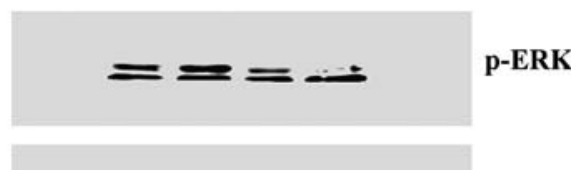

ERK

p-JNK

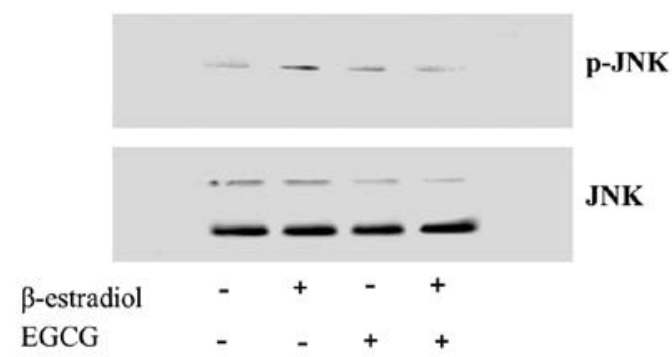

Figure 4. Representative western blotting showing the effect of EGCG on the expression of pAkt and MAPK. The cells were exposed to EGCG for $24 \mathrm{~h}$, and cell lysates were prepared. The expression level of phosphorylated Akt and MAPK proteins were determined by western blotting using the specific antibodies followed by chemiluminescent detection as described in Materials and methods. Equal amounts of cell lysate protein were analyzed in each lane. $\beta$-actin was used as a control. (A) p-Akt expressions of EGCG treated groups were lower than other groups. (B) p-ERK and p-JNK expressions were lower in the EGCG treated groups as well. Representative data are shown from three different experiments.

EGCG disturbs the Akt pathway in Ishikawa cell proliferation treated with $E_{2}$. In case of estrogen-dependent cells, estrogen induces cell proliferation and metabolic activity via PI3K-Akt signal and its downstream mitogen activated protein kinase (MAPK) (8). To study the effect of EGCG on Akt cell survival pathway, phosphorylation status of Akt and expression of its downstream signal MAPK was studied in Ishikawa cells (Fig. 4). Immunoblots showed that EGCG decreased the intracellular levels of phosphorylated Akt (Fig. 4A), and Akt downstream MAPK, ERK and JNK also decreased. Estrogen receptor belongs to steroid hormone nuclear receptor superfamily, and they are ligand-activated transcription factors involved in cellular proliferation and differentiation. They are translocated from the plasma membrane to the nucleus and are mediated by MAPK activation (1). This suggests EGCG regulate cell proliferation by the Akt signal and MAP kinase activation.
EGCG induces apoptosis in Ishikawa cells. We next assessed the effect of EGCG on the induction of apoptosis in Ishikawa cells by FACS analysis. To analyze the apoptosis quantitatively, Ishikawa cells treated with EGCG were examined by flow cytometric analysis to determine the total DNA content of each cell (Fig. 5A). In the present study, we observed that EGCG treatment increased the apoptotic regions of T2 and T4 through the accumulation of sub-G1 cells (Fig. 5B).

EGCG induces apoptotic genes in Ishikawa cells. After EGCG treatment of Ishikawa cells, apoptosis-related proteins, such as caspase-6, 8, 10, Bcl-2, and Bax, were upregulated in $E_{2}$ treated cells. The results revealed that EGCG causes significant downregulation of the anti-apoptotic gene, Bcl-XL (Table III). By quantification of Bax and Bcl family mRNA, it was found that EGCG increase the Bax/Bcl family ratio. EGCG may induce apoptosis by altering the $\mathrm{Bax} / \mathrm{Bcl}$ 
$\mathbf{A}$

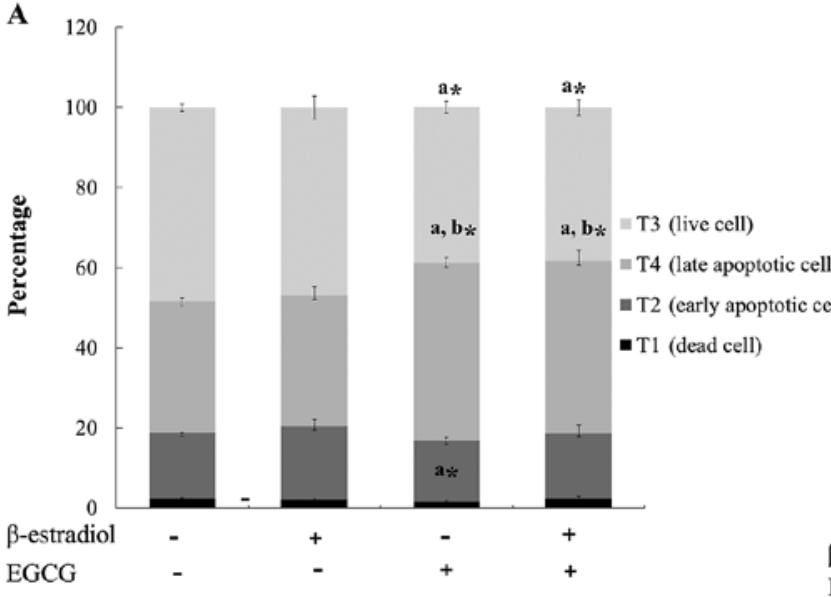

B

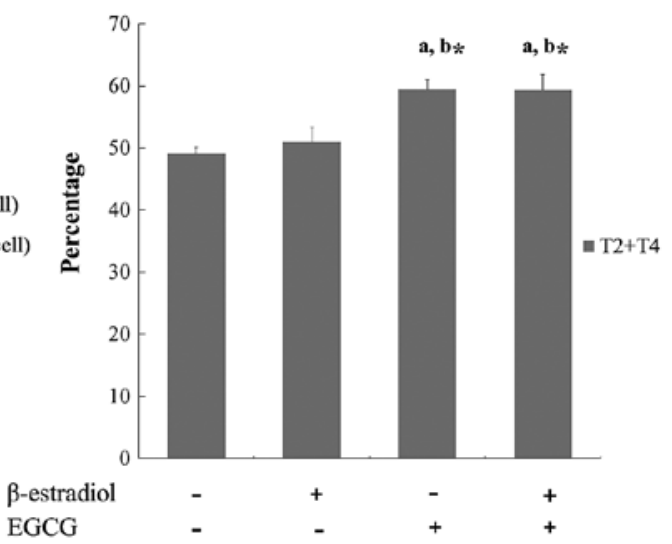

Figure 5. Effect of EGCG on apoptosis by flow cytometric analysis. (A) Flow cytometric analysis of Annexin-V binding in Ishikawa cells after 24-h culture with EGCG in the absence or presence of $\mathrm{E}_{2}$. $\mathrm{AV}^{+} / \mathrm{PI}$, viable cells; $\mathrm{AV}^{-} / \mathrm{PI}^{+}$, necrosis cells; $\mathrm{AV}^{+} / \mathrm{PI}^{-}$and $\mathrm{AV}^{+} / \mathrm{PI}^{+}$, apoptotic cells. The percentage of cell fraction with SEM was calculated based on three independent experiments. (B) The percentages of apoptosis in EGCG treated cells were higher than those of untreated cells. ${ }^{\mathrm{a}} \mathrm{vs}$ control; ${ }^{\mathrm{b}} \mathrm{vs} \mathrm{E}_{2}$ only treated. $\mathrm{p}<0.05$.

Table III. Effect of EGCG on $\mathrm{E}_{2}$ stimulated gene expression of apoptosis from Ishikawa cells.

\begin{tabular}{lcccc}
\hline & \multicolumn{3}{c}{ Treatment } \\
\cline { 2 - 5 } Gene & None & $\beta$-estradiol & EGCG & $\beta$-estradiol+EGCG \\
\hline Caspase-6 & $0.965 \pm 0.376$ & $0.933 \pm 0.279$ & $1.571 \pm 0.955$ & $1.608 \pm 0.102^{\mathrm{b}, \mathrm{c}}$ \\
Caspase-8 & $1.268 \pm 0.120$ & $0.823 \pm 0.348$ & $1.718 \pm 0.344$ & $1.132 \pm 0.392$ \\
Caspase-10 & $1.022 \pm 0.088$ & $0.735 \pm 0.197$ & $1.592 \pm 0.408$ & $0.871 \pm 0.131^{\mathrm{b}, \mathrm{c}}$ \\
Bcl-XL & $1.275 \pm 0.076$ & $1.183 \pm 0.094$ & $0.592 \pm 0.054^{\mathrm{a}, \mathrm{c}}$ & $0.454 \pm 0.013^{\mathrm{b}, \mathrm{c}}$ \\
Bcl-2 & $1.453 \pm 0.143$ & $1.060 \pm 0.257$ & $1.77 \pm 0.316$ & $1.183 \pm 0.490$ \\
Bax & $1.266 \pm 0.126$ & $0.970 \pm 0.218$ & $1.694 \pm 0.324$ & $1.198 \pm 0.114^{\mathrm{b}, \mathrm{c}}$ \\
\hline
\end{tabular}

The cells were cultured for $24 \mathrm{~h}$ and treated with EGCG. Total RNA was isolated from these cells and the expression of caspase-6, $-8,-10, \mathrm{Bcl}$ and Bax genes were examined by quantitative real-time PCR. The expression level of each gene was normalized to GAPDH. Each experiment was performed in triplicate. ${ }^{\mathrm{a}} \mathrm{vs}$ control; ${ }^{\mathrm{b}} \mathrm{vs} \mathrm{E} 2$ only treated. ${ }^{\mathrm{c}} \mathrm{p}<0.05$.

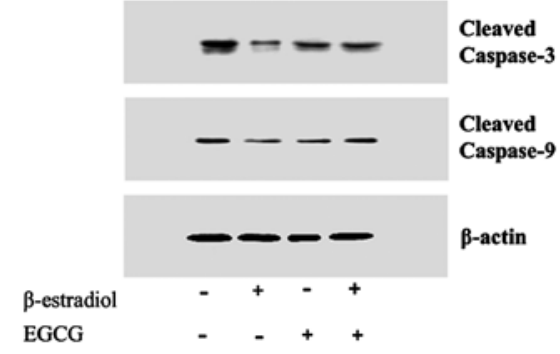

Figure 6. Effect of EGCG on the expression of cleaved caspase-3 and -9. The expression level of cleaved caspase- 3 and -9 were determined by western blotting. Cells were treated with the indicated concentrations of EGCG for $24 \mathrm{~h}$. The total cell lysates were prepared for SDS-PAGE followed by western blot analysis and chemiluminescent detection. Equal amounts of cell lysate protein $(50 \mu \mathrm{g})$ were analyzed in each lane. $\beta$-actin was used as a control to correct for loading. Higher densities were expressed in EGCG treated groups.

family ratio and controlling the initiating caspases. Western blot analysis showed that EGCG increased the level of cleaved caspase-3 and -9 (Fig. 6).

\section{Discussion}

In agreement with previous experimental studies demonstrating the anticancer effect of EGCG using various cell lines, we also found that EGCG had anticancer effect on an endometrial cancer cell line in vitro. Endometrial cancer is one of the most significant gynecological malignancies in the world and accounts for almost 50,000 deaths worldwide per year (18). It is well known that estrogen plays an important role in carcinogenesis of endometrial cancer. There have been many studies demonstrating the relationship between unopposed estrogen exposure and endometrial cancer occurrence $(4,19)$. EGCG, one of the major catechins in green tea, is found in $50-80 \%$ of green tea and shows anticancer properties through blocking multiple signaling pathways, thereby causing strong cancer chemopreventive effects (23). Although the anticancer effects of EGCG has been reported in many studies, we could not find the molecular mechanisms on endometrial cancer cells. Thus, this study is the first trial to verify the anticancer effect of EGCG on an endometrial cancer cell line in vitro. 
Ishikawa cells are one of the best characterized of human endometrial cancer cell line derived from a well differentiated adenocarcinoma and expresses functional steroid receptors of estrogen, progesterone, and androgen (20). In the present study, we used $1 \mu \mathrm{M} \mathrm{E}_{2}$ to induce estrogen receptor upregulation. It would be considered that $\mathrm{E}_{2}$ treatment provides more physiologic environment to the cell culture because the endometrial tissue is grown by estrogen secreted from ovary during reproductive life. Estrogen receptors are upregulated maximally in the late proliferative phase when the serum estrogen level is the highest during the menstrual cycle (21). We found that estrogen and progesterone receptor mRNAs were downregulated in the cells treated with both $\mathrm{E}_{2}$ and $\mathrm{EGCG}$, but not in EGCG only treated cells (Fig. 2). In a previous study on EGCG effect on endometriosis, EGCG inhibited vascular endothelial growth factor (VEGF) expression in endometrial glandular cells and stromal cells stimulated with $\mathrm{E}_{2}$. It was considered that the decreased VEGF expressions might be due to the ability of EGCG competing with $\mathrm{E}_{2}$ for binding to ER- $\alpha$ (21). Considering the lower expressions of ER- $\alpha$ and progesterone receptor mRNA from this study, EGCG might disturb the process of estrogen and progesterone receptor synthesis in the cells stimulated by estrogen. However, more studies would be necessary to obtain the exact mechanism of EGCG on estrogen receptor. Irrespectively, EGCG might be applied as an alternative therapeutic trial to the disorders characterized by estrogen-dependent growth, such as endometriosis, endometrial hyperplasia and breast cancer.

The extracellular signal regulated protein kinases (ERK), the $\mathrm{c}-\mathrm{NH}_{2}$-terminal kinases (JNK), and the p38 MAPKs have been considered as three major MAPKs and activated Akt plays a key role in signaling for cell growth, cell survival (anti-apoptotic) and cell cycle progression. We could find that ERK, JNK and Akt phosphorylations were reduced more in the EGCG treated cells than control or $\mathrm{E}_{2}$ only treated cell (Fig. 4). These results suggest that EGCG have inhibitory effects on cell proliferation and differentiation through MAPK and Akt pathway. These findings are consistent with other studies on human colon cancer cells demonstrating that EGCG inhibited the activation of ERK and Akt $(22,23)$.

We analyzed the enzymes involved in apoptosis processes, cleaved caspase-3 and -9 . Increased expressions were observed in the cells co-treated with $\mathrm{E}_{2}$ and EGCG, when we compared with $\mathrm{E}_{2}$ only treated cells (Fig. 6). Quantitative real-time PCR was used to compare the expression levels of apoptosis related enzyme and proteins implicated in the cancer cell survival. Caspase- 6 and -10 expressions in cells co-treated with $\mathrm{E}_{2}$ and EGCG were increased. Bcl-XL, an anti-apoptotic protein, was decreased, but bcl-2 level was not changed (Table III). Proportions of apoptotic cells treated with EGCG were higher than the control cells regardless of $\mathrm{E}_{2}$ treatment (Fig. 5). These results suggest that EGCG induces apoptosis on Ishikawa cells stimulated with or without $\mathrm{E}_{2}$. Since the apoptotic effect of EGCG on cancer cells published in 1997, subsequent studies verified the effect in various cell types, such as lung, colon, pancreas, skin, and prostate $(24,25)$, but, there have been no report on the apoptotic effect of EGCG on endometrial cancer cells.

Cell cycle dysregulation by cylin-dependent kinase (CDK) activity is generally observed in human malignant cells. In the present study, we found that Cdk1, Cdk2 and cyclin D3 mRNA expressions in ECGC and $\mathrm{E}_{2}$ co-treated cells were decreased, comparing with the cells treated with $\mathrm{E}_{2}$ only (Table II). In flow cytometric analysis, we observed that the percentage of G0/G1-phase cell cycle arrest in EGCG treated cells was more than that of $E_{2}$ only treated cells (Fig. 3). This fact implies that EGCG inhibits cell cycle progression by decreasing Cdk 1, Cdk 2 and cyclin D3 of cells treated with $\mathrm{E}_{2}$. Therefore, it is suggested that EGCG shows an inhibitory effect on Ishikawa cell cycle progressions as previous studies have been reported $(26,27)$.

Clinical trials to apply EGCG to the cancer patients have been performed. A few studies have reported the effectiveness in human papilloma virus-infected cervical lesion and androgen independent prostate cancer $(28,29)$. In the case of endometrial cancer or estrogen-dependent disease, the present study would provide the beginning of clinical application.

Conclusively, the present study demonstrates for the first time that EGCG inhibits proliferation and induces apoptosis of the endometrial cancer Ishikawa cells in vitro. Estrogen and progesterone receptor expressions are also decreased among the cells co-treated with $\mathrm{E}_{2}$ and EGCG. Thus, EGCG, major component of green tea, might have therapeutic or chemopreventive effect on endometrial cancer or estrogen-related disorders.

\section{Acknowledgements}

This study was supported by the Dong-A University Research Fund.

\section{References}

1. Doll A, Abal M, Rigau M, et al: Novel molecular profiles of endometrial cancer-new light through old windows. J Steroid Biochem Mol Biol 108: 221-229, 2008.

2. Albrektsen G, Heuch I, Tretli S and Kvale G: Is the risk of cancer of the corpus uteri reduced by a recent pregnancy? A prospective study of 765,756 Norwegian women. Int J Cancer 61: 485-490, 1995.

3. Kalandidi A, Tzonou A, Lipworth L, Gamatsi I, Filippa D and Trichopoulos D: A case-control study of endometrial cancer in relation to reproductive, somatometric, and life-style variables. Oncology 53: 354-359, 1996.

4. Grady D, Gebretsadik T, Kerlikowske K, Ernster V and Petitti D: Hormone replacement therapy and endometrial cancer risk: a meta-analysis. Obstet Gynecol 85: 304-313, 1995.

5. Akhmedkhanov A, Zeleniuch-Jacquotte A and Toniolo P: Role of exogenous and endogenous hormones in endometrial cancer: review of the evidence and research perspectives. Ann NY Acad Sci 943: 296-315, 2001.

6. Holinka CF, Anzai Y, Hata H, Kimmel N, Kuramoto H and Gurpide E: Proliferation and responsiveness to estrogen of human endometrial cancer cells under serum-free culture conditions. Cancer Res 49: 3297-3301, 1989.

7. Bouskine A, Nebout M, Mograbi B, Brucker-Davis F, Roger C and Fenichel P: Estrogens promote human testicular germ cell cancer through a membrane-mediated activation of extracellular regulated kinase and protein kinase A. Endocrinology 149: 565-573, 2008.

8. Castoria G, Migliaccio A, Bilancio A, et al: PI3-kinase in concert with Src promotes the S-phase entry of oestradiol-stimulated MCF-7 cells. EMBO J 20: 6050-6059, 2001.

9. Robertson JA, Farnell Y, Lindahl LS and Ing NH: Estradiol up-regulates estrogen receptor messenger ribonucleic acid in endometrial carcinoma (Ishikawa) cells by stabilizing the message. J Mol Endocrinol 29: 125-135, 2002.

10. Cheskis BJ, Greger J, Cooch N, et al: MNAR plays an important role in ERa activation of Src/MAPK and PI3K/Akt signaling pathways. Steroids 73: 901-905, 2008. 
11. Wolpin BM and Mayer RJ: Systemic treatment of colorectal cancer. Gastroenterology 134: 1296-1310, 2008.

12. Fujiki H, Suganuma M, Okabe S, et al: Japanese green tea as a cancer preventive in humans. Nutr Rev 54: S67-S70, 1996.

13. Pan MH, Chiou YS, Wang YJ, Ho CT and Lin JK: Multistage carcinogenesis process as molecular targets in cancer chemoprevention by epicatechin-3-gallate. Food Funct 2: 101-110, 2011.

14. Webb T: Green tea experiments in lab, clinic yield mixed results. J Natl Cancer Inst 92: 1038-1039, 2000.

15. Cao Y and Cao R: Angiogenesis inhibited by drinking tea. Nature 398: 381, 1999.

16. Yokoyama M, Noguchi M, Nakao Y, Pater A and Iwasaka T: The tea polyphenol, (-)-epigallocatechin gallate effects on growth apoptosis, and telomerase activity in cervical cell lines. Gynecol Oncol 92: 197-204, 2004

17. Zhang G, Gurtu V, Kain SR and Yan G: Early detection of apoptosis using a fluorescent conjugate of annexin V. Biotechniques 23 525-531, 1997.

18. Parkin DM, Bray F, Ferlay $\mathbf{J}$ and Pisani P: Global cancer statistics, 2002. CA Cancer J Clin 55: 74-108, 2005.

19. Beral V, Bull D and Reeves G: Endometrial cancer and hormonereplacement therapy in the Million Women Study. Lancet 365: $1543-1551,2005$.

20. Lovely LP, Appa Rao KB, Gui Y and Lessey BA: Characterization of androgen receptors in a well-differentiated endometrial adenocarcinoma cell line (Ishikawa). J Steroid Biochem Mol Biol 74: 235-241, 2000.

21. Snijders MP, de Goeij AF, Debets-Te Baerts MJ, Rousch MJ, Koudstaal J and Bosman FT: Immunocytochemical analysis of oestrogen receptors and progesterone receptors in the human uterus throughout the menstrual cycle and after the menopause. J Reprod Fertil 94: 363-371, 1992.
22. Shimizu M, Deguchi A, Lim JT, Moriwaki H, Kopelovich L and Weinstein IB: (-)-Epigallocatechin gallate and polyphenon E inhibit growth and activation of the epidermal growth factor receptor and human epidermal growth factor receptor-2 signaling pathways in human colon cancer cells. Clin Cancer Res 11: 2735-2746, 2005.

23. Khan N, Afaq F, Saleem M, Ahmad N and Mukhtar H: Targeting multiple signaling pathways by green tea polyphenol (-)-epigallocatechin-3-gallate. Cancer Res 66: 2500-2505, 2006.

24. Ahmad N, Feyes DK, Nieminen AL, Agarwal R and Mukhtar H: Green tea constituent epigallocatechin-3-gallate and induction of apoptosis and cell cycle arrest in human carcinoma cells. J Natl Cancer Inst 89: 1881-1886, 1997.

25. Yang CS, Maliakal $P$ and Meng X: Inhibition of carcinogenesis by tea. Annu Rev Pharmacol Toxicol 42: 25-54, 2002.

26. Ahmad N, Cheng P and Mukhtar H: Cell cycle dysregulation by green tea polyphenol epigallocatechin-3-gallate. Biochem Biophys Res Commun 275: 328-334, 2000.

27. Liu X, Zhang DY, Zhang W, Zhao X, Yuan C and Ye F: The effect of green tea extract and EGCG on the signaling network in squamous cell carcinoma. Nutr Cancer 63: 466-475, 2011.

28. Ahn WS, Yoo J, Huh SW, et al: Protective effects of green tea extracts (polyphenon E and EGCG) on human cervical lesions. Eur J Cancer Prev 12: 383-390, 2003.

29. Jatoi A, Ellison N, Burch PA, et al: A phase II trial of green tea in the treatment of patients with androgen independent metastatic prostate carcinoma. Cancer 97: 1442-1446, 2003. 